\title{
Teaching and Research: Their Relation in the University
}

\author{
JAMES B. HARTMAN*
}

Within the context of the continual debates concerning the basic functions of the university, there is little disagreement that its most general aim is the pursuit of truth and knowledge. This activity customarily takes two forms: research, which may be defined as any creative acts or systematic and disciplined investigation into the phenomena of human experience that advances the sum of knowledge, and teaching, the transmission of culture, knowledge, and the accumulated results of scholarly activity, with the further aims of training students for specific vocations and professions, preparing them for a life of responsible citizenship, and the cultivation of the intellect for its own sake. Research, then, emphasizes the generation, creation, invention, and discovery of knowledge, while teaching refers to its transmission, dissemination, communication, and interpretation.

\section{Conflict between Teaching and Research}

The question of the proper relation between teaching and research in the life of the individual faculty member and in colleges and universities generally has been the topic of much dispute. Frequently the problem is defined in terms of an inherent conflict between the two, as exhibited in the predicament of the individual faculty member:

Perhaps the leading problem for the individual faculty member is the incongruity between his job assignment and the work which determines his success or failure in his own discipline. As we have seen, most faculty members are hired to teach students and to bear their share of responsibility for the normal operation of the university as an educational organization. These are the duties for which they are paid and which they must perform. Although in most occupations men are judged by how well they perform their normal duties, the academic man is judged almost exclusively by his performance in a kind of part-time voluntary job which he creates for himself. Not only does his career depend on these supplementary efforts, but there is a tendency for his superiors to punish successful performance of the tasks for which he is hired. It is only a slight exaggeration to say that academic success is likely to come to the man who has learned to neglect his assigned duties in order to have more time and energy to pursue his private professional interests. (1)

\footnotetext{
* James B. Hartman teaches Philosophy at Scarborough College, University of Toronto and is also engaged in research studies in higher education.
} 
A recognition of the prevalence and severity of these conditions has prompted some observers to formulate the problem as one of the dilemma of teaching versus research, (2) which suggests some sort of inherent incompatibility between the two types of activity.

\section{Historical Background}

The conditions which contribute to the existence of this alleged conflict have not always existed, so the current situation may better be understood by a brief review of the historical development of the university and the reasons for the appearance of this problem on the contemporary scene.

In its earliest beginnings, a university was a society of masters and students, largely self-governing and free of external control, organized for the purpose of preparing professionals in the fields of medicine, law, theology, philosophy, and eventually in the natural sciences. The first university degrees were in fact licences to teach, and many of the holders of the professor's licence were excellent and renowned teachers. The methods of instruction employed in medieval universities in the days of few books and no laboratories consisted largely of formal lectures, which included summaries, corrections, general principles, and the like, along with less formal reviews and disputations, and the public defence of a thesis. The medieval student, on completion of his training and receipt of his degree, diploma, or licence, was recognized as qualified to practice a particular art or profession. A master, on the other hand, if he tired of teaching, might seek a stipend from a wealthy patron to return to university for a higher degree which eventually could lead to royal or ecclesiastical honours, often lucrative.

Teaching, in the sense of the dissemination of knowledge, clearly was the main function of the early university, and success or failure in the profession was largely determined by the surveillance, often coercive and tyrannical, of the organized student body. Since fees were paid directly by students to their professors, there was a highly effective incentive for outstanding teaching performance! Scholarship, in the sense of the invention, discovery, or advancement of new knowledge was an accomplishment of the more talented. While not required of the early professor, original scholarly activity was nevertheless much revered when it occurred.

In the subsequent history of the university, there were two developments which favoured an emphasis on scholarly research. In his Advancement of Learning, published in 1605, Francis Bacon, the philosopher of the new scientific movement, criticized the emphasis on professional studies in the universities and the corresponding neglect of the arts and sciences which he believed could provide the foundations of learning. He deplored the lack of experimental work which hindered the development of the natural sciences and remarked on the need to identify unexplored areas and undeveloped forms of knowledge. In Bacon's view, the aim of knowledge was to give power over nature, and without a proper method (induction) an understanding of the inner workings of natural phenomena, which would provide the basis for this control, could never be achieved. Prior to the application of scientific method, Bacon advocated an appropriate arrangement and classification of what was then known and the identification of future areas of discovery. Although Bacon never succeeded in putting this grandiose scheme into practice, his ideas had a great impact on educational thought in the seventeenth century and succeeding 
times. It was undoubtedly due to his influence that one of the ideals of modern education became the advancement of knowledge: the discovery and generation of new knowledge through methodical techniques of scholarly research.

The other major influence lay in the program of educational reconstruction carried out by F.W. von Humboldt, appointed director of public instruction in Germany in 1808. It was due to his efforts that the University of Berlin was established and, along with it, a new conception of university work in which the main emphasis was on scientific research, rather than on teaching and the examining of students. Accordingly, professors were appointed on the basis of their capacity to make original contributions to knowledge. At the same time, von Humboldt also reformed secondary schools, some of which were designated as university preparation institutions, and he instituted special examinations for these secondary school teachers. Thus, the separation between research, on the one hand, and professional teaching activity, on the other, was firmly established. A desirable consequence of these reforms, and the emphasis on scholarship and research in higher education, was that professors and students in the German university became much more analytical and critical, and less authoritarian and dogmatic in their intellectual outlook.

To a great extent, the ideals of the German university were a part of the development of universities in the United States in the late nineteenth century. Prior to the Civil War, much of the education which took place in small local colleges consisted of enforced rote learning of an anti-intellectual, non-critical sort. However, the importation of German ideas and the emphasis on research directly affected the orientation of newly established graduate schools towards the end of the century and became the catalyst for the emergence of the intellectual spirit in American education. (3) At the same time, the establishment of land-grant colleges in the United States, with their practical courses and close relationship with their immediate state governments and local agencies, initiated a tradition of teaching, applied research, and public service.

Canadian universities, however, have been affected not only by developments on the American scene, but by the diverse influences of the cultural heritages of English and Scottish universities. (4) The function of English universities in the nineteenth century was to prepare leaders of the Establishment by teaching high English culture. In this conservative context, the advancement of knowledge was of small concern. In Scottish universities of the same period intellectual inquiry and the discovery of knowledge was carried on by teachers of undergraduate students. Since English universities did not allow the research function to dominate their teaching function, members of the academic staffs of English universities who came to Canada during the first half of the present century brought with them their values of the primacy of undergraduate education. During the last twenty-five years, however, the American influence, with its derived German emphasis on graduate study and research, increasingly has pervaded the Canadian scene, partly through Canadians themselves who received graduate training in the United States. At the same time, the American land-grant influence has been felt in some parts of the country. Universities in French-speaking Canada remained for a long time modelled on medieval universities and maintained a religious orientation, but in recent times have been more inclined to adopt the patterns of English-speaking Canadian universities than those of modern French universities. Thus the historical presumption of the inextricability of 
intellectualism and formal research found in American universities, together with the countervailing cultural influences of the English and American patterns interacting on the Canadian scene, underly disputes about the conflict between research and teaching in the contemporary university.

\section{Intensification of the Conflict}

In the present century, several other developments have contributed to the intensification of the conflict between teaching and research, and two of the most important are the growth of professionalism in the sciences and the increase in on-campus research. (5) Professionalism in the sciences has increased markedly with the establishment of formal professional associations and organizations which shared overlapping membership with the universities. A consequence of this development has been the emergence of a new set of attitudes among faculty members and administrators alike. The individual faculty member has come to regard himself and his colleagues as members of a group of professionals whose sphere of activity, influence, and loyalty extends far beyond the boundaries of the university. This, in turn, has brought about a shift in the system of academic rewards within the university.

More recently, in response to the demands of government, business, and industry, there has taken place a massive growth of on-campus research. The university has begun to act as an agency for public good, in many instances, supplying practical benefits to the community through the expansion of research programs in the areas of mental health, adult education, environmental studies, and other various forms of community service. The university has always occupied a position as the center of knowledge; now it has become the center of research and scientific investigation. Through positive feedback, this activity has been further stimulated by new funds, with increasingly higher salaries paid to researchers and scientific superstars. Also, various foundations offer research grants to young scholars for periods free of teaching duties.

A consequence of the increasing emphasis on research in the sciences has been to encourage the spread of the research orientation to other disciplines. It has been argued, for example, that the humanities have been subverted from their original and proper educational mission, the molder of men.(6) Apart from the isolated temporary appointments of writers, musicians, and artists-in-residence, the recruitment of faculty in the humanities is now exclusively from graduate institutions. Their graduates, thoroughly accustomed to the values and attitudes of research-oriented departments, import these values into their new teaching appointments, thus altering the nature of the departments and colleges which they join. Teaching, then, may come to be regarded as a secondary activity and tolerated as a necessary evil.

The problem of the evaluation of the effectiveness of the faculty is also very intimately connected with the exacerbation of the conflict between teaching and research. In past years, when college and university enrolments were relatively low, departments were small and intimate and the faculty was relatively non-mobile. In this context, informal means of judging the quality of colleagues were the rule. Now, however, departments have in many cases grown to enormous size and faculty members come and go with increasing frequency. The need to establish some formal means of assessment has been met 
by giving attention to the most visible and easily measured activity, research. The researcher's awards, grants, fellowships, scholarships, governments contracts, memberships in professional societies, appointments to commissions, and published articles all testify most vividly to his unrelenting activity on the frontiers of knowledge. Teaching, on the other hand, is largely invisible to those charged with the evaluation of the effectiveness of the faculty member and is perhaps more difficult to assess. Disagreements concerning the validity of measurements of teaching ability and an unwillingness to accept student opinions and assessments have contributed to the relative unimportance granted to teaching in decisions relating to appointments, promotion, tenure, and merit salary increases. While the difficulties involved are not insuperable, the tendency of administrators is to take the path of least effort and to proceed on the doubtful premise that proficiency in research guarantees proficiency in teaching, a view not readily acceptable to devoted and capable teachers and their students.

The shift in emphasis from education to research has brought about other effects on curriculum and students alike. In the early university, the curriculum was determined by the demands of the students as they perceived their practical vocational and professional needs. Now the research interests of the faculty members frequently influence at least part of the curriculum, particularly in the upper-level undergraduate and graduate-school settings, with little regard for the needs of students with heterogeneous interests and varied academic abilities and motivations. There is always the likelihood that certain elements of curricular programs will be defined in terms of what faculty members or committees believe the students ought to have, as determined by the research orientation of the faculty, rather than what the students want and need in terms of their unique intellectual and vocational goals. Thus the original function of the university has been subverted; the tail is now wagging the dog, with occasional twists of the tail supplied by government, industry, and other outside agencies having vested interests in the production of certain types of professional personnel.

Another feature of university life that intensifies the conflict between teaching and research is the matter of priorities in the light of available resources. Clearly there is no problem when resources are adequate throughout the system. However, in times of economic stringencies, departments that are over-staffed and suffer from unfavourable staff-student ratios, often are inclined to dismiss non-producers first, even though they may be good teachers, thus encouraging greater enthusiasm for research activity on the part of the remaining untenured staff. This process indirectly but clearly affects the priorities of the university towards research and perhaps, but not necessarily, away from teaching.

\section{Relations between Teaching and Research}

Any account of the conflict between teaching and research must confront the question of the connections, both for good and for ill, that may hold between the two. In this connection, there are considerations either of quantitative or of qualitative sorts.

First, let us consider the matter of the effects of teaching on research from the quantitative point of view. For example, it can be argued that, simply on the issue of finite available time, the more that is given to teaching, the less can be devoted to research acti- 
vity. This consideration is at the basis of discussions about proper faculty workload. At the same time, it should be noted that recent moves to increase teaching loads for economic reasons, favoured by the public and politicians alike, will have the effect of further diminishing available time for research. This in turn will intensify the conflict in the individual faculty member, who must make a choice on the distribution of time and effort.

On the other hand, there are some qualitative considerations to support the contention that teaching has a favourable effect on research. Association with intelligent, alert, and critical students will provide the stimulation and constant questioning of ideas so necessary to the conduct of original inquiry. Without the necessary feedback, both positive and negative, the isolated researcher remains at a distinct disadvantage to his teaching colleague. At the same time, a more basic psychological factor may be at work. It has been argued that it is perhaps not so much the specific stimulation of students that favourably affects the activity of the teacher-researcher, but the introduction of any element of diversity into the faculty member's life that is likely to produce a beneficial effect on research activity.(7) So, not only a lighter teaching load but other diversified types of activity might be expected to increase research productivity, all other things being equal.

The question of the effects of research on teaching is somewhat more involved, but again it might be approached from both quantitative and qualitative perspectives. While it may be generally true that lively exploratory activity contributes to good teaching in certain contexts, the difficult question-mainly an economic one-is how much research activity is required to produce a given improvement in teaching, and hence in the studentproduct? Using the converse version of the quantitative time argument stated above, it is evident that the greater the amount of time given to research, the less can be spent on teaching, course preparation, conferring with students, and the like. In fact, undergraduate students generally believe that the time their professor spends outside the classroom, apart from his preparation and office hours, is unrelated to teaching and therefore is time denied them. Further, if they happen to know that the professor is heavily involved in research, they conclude that he spends little time in the preparation of courses and lectures. From the students' perception of the matter, teaching is the most visible feature of the faculty member's performance and research is the least visible. Politicians, boards of governors, and the public are likely to share this view, for the same reasons. They, too, often regard teaching as simply the transmission of knowledge, perhaps repetitive, and are therefore easily convinced of the wisdom of proposals to increase faculty teaching loads.

From the qualitative aspect, administrators and faculty often assume that research activity contributes to good teaching. In some respects, administrators in particular are forced to operate on this view, since research activity is the most visible feature of the faculty member's performance, while teaching is not. This misperception is reflected in a "unidimensional conception of academic worth," (8) a criterion of judgment which assumes that if the more visible activity is done well, the less visible activity must be done equally well. While an opinion survey reported that students gave higher teaching ratings to faculty members who had published or were receiving research grants, (9) this need not prove that research activity contributes to effective teaching; it may simply indicate that 
superior individuals both teach well and are active researchers. Thus, the belief that productive research activity somehow guarantees good teaching is not substantiated.

In addition, it might be asked, does the content of research affect the quality of teaching? The question can only be answered by distinguishing between junior-level undergraduates, on the one hand, and senior-level undergraduates and graduate students, on the other. With regard to the former, research activity on the part of the faculty member may affect teaching quality adversely, making introductory courses over-specialized and detracting from the necessary breadth and integration of knowledge which lower-level teaching requires. However, the teacher of upper-level undergraduates and graduate students may engage them in projects on the frontiers of knowledge, either in relation to his own interests or to their vocational and professional careers. It has been argued that activity in frontier research should be required of teachers of graduate students in the sciences, although their needs should not be made the criterion for the whole student body.(10) For these reasons, then, the general claim that research activity has a favourable effect on teaching quality cannot be accepted without qualification.

The difficulty and obscurity of the question of the relation between teaching and research is due to at least two complicating factors: the definition of a "good" faculty member, and the nature of the academic reward system. In turn, these factors must be qualified from two different perceptual points of view: the academic administrator's and the students', each involving "contrary assumptions of adequacy."(11)

The administrator, having charge of various staffing procedures relating to hiring, promotion, tenure, and merit salary increases, seeks to maximize good research capability and effective teaching. However, due to the inherent invisibility of the latter function, rewards inevitably go to the researcher, whose productions are most visible. This tendency is encouraged by the faulty belief, referred to above, that good research implies good teaching. Consequently, due to ignorance, laziness, or deliberate disregard, the university must settle for less than the ideal, rewarding good researchers only, and punishing (by denial of tenure, promotion, or merit salary increases) those faculty members who are both poor researchers and poor teachers, and those who are less effective researchers than teachers. For the administrator, then, the "good" faculty member, for all practical purposes, is the productive researcher.

From the student point of view, however, a "good" faculty member is synonymous with the stimulating, knowledgeable, effective classroom instructor, and students acknowledge them by favourable judgments in teaching and course evaluations, wherever they are employed. But, by the nature of the academic reward system, they are required to tolerate the good researcher-poor teacher, usually a tenured faculty member, who has secured the blessings of the academic-administrators. Equally visible to the students are those good teachers-poor researchers who are let go.

On the whole, and perhaps at only a small risk of oversimplification, it seems safe to say that there is an increasing tendency for only good researchers to be hired or retained on university staffs, regardless of their teaching ability, while good teachers and poor ones alike tend to be let go if they do not exhibit substantial research activity. Thus, the locus of the conflict and the source of the anxiety of the individual faculty member is found in the inadequacy of the academic organization and, in particular, in its inefficient 
and unjust reward system which tends to pay insufficient attention to the teaching function, to the ultimate detriment of the educational process. The dual requirements of teaching for the university and publishing for the profession generate a dilemma for the individual faculty member in which the norms for each role are in contradiction. At this point, it is appropriate to raise the question: should the individual faculty member be required to conform to the present system, productive of conflict, or should the academic organization be changed in ways which will recognize individual differences and attempt to meet varying needs and capabilities through instituting certain reforms in structure and procedures? Consideration of this problem will be deferred until later in this discussion.

\section{Separation or Integration?}

To resolve the teaching-research conflict, some account of the respective merits of separating or combining teaching and research must be given. In the following discussion, it will be assumed that arguments for separation will be the same as those against integration, and vice versa.

Arguments for the separation of the two functions generally are based on the contention that the current over-emphasis on research has undesirable effects on several aspects of the educational process. These unfortunate consequences may not, in fact, be avoidable if they are products of a basic philosophical difference underlying the conflict between teaching and research: researchers regard themselves and others as means for the advancement of knowledge, while teachers, as educators, regard knowledge not as an end in itself, but as a means to further the intellectual development of people.(12) Failure to acknowledge this difference conceivably could have disruptive effects both on faculty-student relationships and on curricula. Research-oriented faculty members may attempt to recruit students to assist them in research projects without due regard for their genuine interests and abilities and to reorganize important segments of the undergraduate program in the light of their conception of the conceived goal of the minority of the student body, graduate study. Add to this the basically incompatible orientations of researchers and teachers-the former specialized and restricted in intellectual interests, the latter wider, less concentrated, and more diversified-and it is clear that at least some of the conflict produced in the present system could be diminished by the separation of teaching and research activities.

In many respects, several of the features of the present situation which were identified earlier as contributing to the intensification of the conflict between teaching and research -the emergence of national foundations underwriting research, the growth of academic professionalism, the rise to power of university departments staffed by research-oriented professors who share each other's ambitions and seek to impose them on others, their promotion of research at the expense of teaching as reflected in staffing policies and decisions, and the provincialism of graduate schools-all these could be brought forward as arguments for the separation of the two functions. An immediate consequence of such a move, according to Arrowsmith, would be to restore teaching to its proper role in assisting the university to meet its responsibilities to the community and to culture. Arrowsmith's conception of the teacher is one whose intelligence, skill, and scholarship will provide a model of integration of knowledge and a life of informed conduct for the 
development of students who prefer a harmonizing education in preference to the inflexible and conformist training in preparation for graduate study.(13) A complementary reason may reside in the uselessness and triviality of much research. Too much concern with the discovery of facts, and too little regard for their significance, has contributed to the superficiality of much research activity which has been described as greatly overestimated, secondary, parasitic, fraudulent, and an enemy of thought.(14)

A significant argument for separation is derived from the recognition that there is no demonstrated connection between ability in research and effectiveness in teaching, as reported by numerous studies in this area which have compared such indicators of academic performance as research productivity, colleague ratings, and student evaluations of teaching.(15)

Some proponents of inseparability of teaching and research frequently adopt the absurd tactic of berating teaching as entertainment and teaching evaluations as popularity contests, while others attempt to rectify the stereotype of the researcher as an inhuman product of the technological world who produces dry knowledge by purely mechanical means. More thoughtful observers, however, claim that research, as the continual, active quest for truth, is not incompatible with teaching, but a desirable complement to it, thus rejecting the belief that a conflict exists between the two. Good teaching, it is claimed, is not antagonistic to research and must be supported by it, not only to provide the necessary path to competence in a field of inquiry, but to safeguard against false or dated knowledge, to avoid repetition, and to assist in achieving fundamental understanding by active participation in practical investigations of various sorts. Although much research may not lead to publication, nevertheless it is the chief avenue through which the results of disciplined learning are communicated to colleagues in similar and related disciplines and to the educated public.

Clearly, a great deal that can be said for the inseparability of teaching and research is based upon anticipated beneficial effects on the development of the faculty member, the improvement of the curriculum, and the enhancement of the learning experiences of the student. The praiseworthy desire to avoid intellectual stagnation through the revitalizing effects of exploratory activity, the need to regenerate teaching by the constant introduction of up-to-date material which will heighten the freshness and authority of advanced courses in particular, and the necessity for a continual exchange of new ideas with involved students and colleagues alike in a creative, interactive environment, all point to the need for integration of teaching and research activities.

\section{Present and Future Reforms}

In some respects, the belief that there is a conflict between teaching and research may be the result of an unduly restricted conception of teaching and research. The idea of research as the discovery of knowledge and teaching as its transmission may well support the claim for their separation in a kind of ideal Platonic academic republic governed by the principle of the proper division of labour. However, if teaching and research are regarded as end points on a continuum in which these functions are for the most part integrated, there is no inherent conflict between them. Any conflict will be the product of administrative structures and procedures that are imposed on this continuum at certain points. In 
short, the presence of conflict is a symptom of maladjustment in the organizational system, but it does not indicate any basic incompatibility between teaching and research.

This conclusion may be approached from a slightly different point of view. As we have seen, the arguments for the integration of teaching and research point to the desirability of enhancing both teaching and learning processes generally, and have their focus on the intellectual development of the individual faculty member and student alike. On the other hand, the arguments for the separation of teaching and research concentrate on those factors, generally of an administrative and organizational sort, which are productive of conflicting behaviour expectations on the part of the individual faculty member and the academic institution, respectively. The problem, therefore, is to seek changes and reforms which will reduce or eliminate the sources of conflict.

To deal with this problem in the context of the present system, the following recommendations are worth considering. First, some change in the definition of professorial roles is desirable, according to individual capabilities. The research professor who pursues his theoretical interest in research institutes, unencumbered by teaching responsibilities, is not an unfamiliar figure on the academic scene. Why not, then, a teaching professor, whose teaching skills and creative use of effective techniques of instruction and learning could be used to devise new methods to elicit the creative responses of students under his direction? Tenured ranks might be devised under this classification and successful achievement judged by appropriate techniques of teaching and course evaluation, just as appropriate criteria for judging research productivity would be applied to the research professor. Eventually, it might be hoped that local, institutional prestige would attach to the teaching professorship, although the disciplinary, cosmopolitan prestige of the researcher is a formidable barrier to match or overcome.

A complementary yet supportive academic role would be found in the university professorship, established on a horizontal basis cutting across traditional departmental lines, which would have the responsibility for general education, interdisciplinary programs, teacher-oriented programs, and perhaps instructional development and teaching evaluation. Ideally, this function would operate as a counteracting force to departmental power which presently encourages research at the expense of teaching.

While purely research professors and teaching professors would likely be in the minority in the university, some provision for the resolution of the conflict for the remainder who may wish to undertake both teaching and research responsibilities must be made. One way of accomplishing this would be for explicit agreements to be reached concerning the anticipated roles of the faculty member during the contractual period of employment on such matters as the relative proportions of teaching, research, administration, public service, etc., and on the criteria for judging success.(16) This, together with a judicious use of students on staffing committees, should materially reduce the anxiety and conflict which is the product of misunderstandings regarding the faculty member's role. Thus, within a particular institution, the conflicting demands of both research and teaching may be met without resorting to the artificial insistence that they should be harmonized in each individual faculty member.(17)

Both research and teaching, whether considered as separate, complementary, or integrated activities, are valid social investments and it is essential that the most effective 
means be devised for developing and fulfilling these functions. Where research and teaching are separated, as they presently are in research institutes and two-year colleges which have unitary goals, no conflict arises. However, in the university, whose faculty plays an ambiguous, dual role, a pluralism of goals must be admitted, but the same pluralism of functions need not be required of each individual, except by explicit agreement.

The university of the future, then, must acknowledge its pluralism of goals and not, as at present, profess teaching as its primary function while actually behaving as if research was more important. More flexible and adaptive organizational and administrative procedures will be required to accommodate the recognition of a multiplicity of equally valid functions for its faculty members. Finally, when the educational process itself is restructured and reformed in such a way as to encourage students to become active participants in the discovery of knowledge, the distinction between research and teaching will eventually diminish and its associated conflicts will disappear.(18)

There still remain some difficult questions underlying the preceding discussion. What is good teaching? Can students judge the content of teaching as well as style and presentation? Are teaching evaluations adequate and reliable indicators of the quality of the learning experience? While the difficulties in judging teaching quality are not insuperable, a more concerted attack on these issues must be made. Likewise, what is good research? Must it be relevant, and how is "relevance" to be defined? How is the conflict between academic freedom to choose research interests and the demand for public accountability to be reconciled? Is there a moral issue involved in the application of the results of basic research? Is all knowledge an unqualified good? Finally, what sorts of complementary interactions between teaching and research should be developed in the future university? Until these and other difficult problems are approached, our understanding of the relation between teaching and research will remain obscure.

\section{Notes}

1 Theodore Caplow and Reece J. McGee, The Academic Marketplace (Garden City, N.Y.: Anchor Books, 1965), p. 189.

2 See, for example, Thomas W. Martin and K.J. Berry, "The Teaching-Research Dilemma: Its Sources in the University Setting," Journal of Higher Education, 40, 1969, pp. 691-703; Phillip E. Hammond, John W. Meyer, and David Miller, "Teaching versus Research: Sources of Misperceptions," Journal of Education, 40, 1969, pp. 682-690.

3 Steven B. Sample, "Inherent Conflict Between Research and Education," Educational Record, 53, 1972 , p. 18.

4 Louis-Phillippe Bonneau and J.A. Corry, Quest for the Optimum: Research Policy in the Universities of Canada. The Report of a Commission to Study the Rationalization of University Research, Vol. 1. Association of Universitjes and Colleges of Canada, 1972, pp. 17ff.

5 Martin and Berry, op. cit., pp. 695-696.

6 William Arrowsmith, "The Future of Teaching," Journal of Higher Education, 38, 1967, p. 132.

7 D.C. Pelz and F.M. Andrews, "Diversity in Research," in The $R$ and D Game, edited by D. Allison. Cambridge, Mass.: M.I.T. Press, 1969, cited by Stephen Black, "Interactions between Teaching and Research," Universities Quarterly, 26, 1962, p. 350.

8 Hammond, Meyer, and Miller, op. cit., p. 688.

9 J.B. Bresler, "Teaching Effectiveness and Government Awards," Science, 1968, pp. 164-167, cited

by Black, op. cit., p. 349.

10 Bonneau and Corry, op. cit., pp. 51-52. 
11 Hammond, Meyer, and Miller, op. cit., p. 689.

12 Sample, op. cit., p. 19.

13 Op. cit., pp. 133,135.

14 P.M. Brannan, "Research in Universities," Universities Quarterly, 21, December 1966, pp. 66-67.

15 E.R. Guthrie, "The Evaluation of Teaching," Educational Record, 30, 1949, pp. 109-115; Virginia V. Voecks, "Publications and Teaching Effectiveness," Journal of Higher Education, 33, 1962, pp. 212-218; Lawrence M. Aleamoni and Makonnen Yimer, An Investigation of the Relationship Between Colleague Rating, Student Rating, Research Productivity, and Academic Rank in Rating Instructional Effectiveness. University of Illinois Research Project \#338, Office of Instructional Resources, March, 1972; Robert G. Cope, John G. McMillin, and Judy M. Richardson, A Study of the Relationship Between Quality Instruction as Perceived by Students and Research Productivity in Academic Departments. Final Report, University of Washington, College of Education, November, 1972 ; Joseph Harry and Norman S. Goldner, "The Null Relationship Between Teaching and Research," Sociology of Education, 45, Winter 1972, pp. 47-60.

16 Bonneau and Corry, op. cit., p. 56.

17 W.G. Fleming, Ontario's Educative Society, vol. 4: Post Secondary and Adult Education (Toronto: University of Toronto Press, 1971), p. 306.

18 Recently, it was estimated that perhaps one-tenth of the undergraduate population in the U.S.S.R. was involved in part-time research, according to Basil Fletcher, Universities in the Modern World (Oxford: Pergamon Press, 1968), p. 58. 